
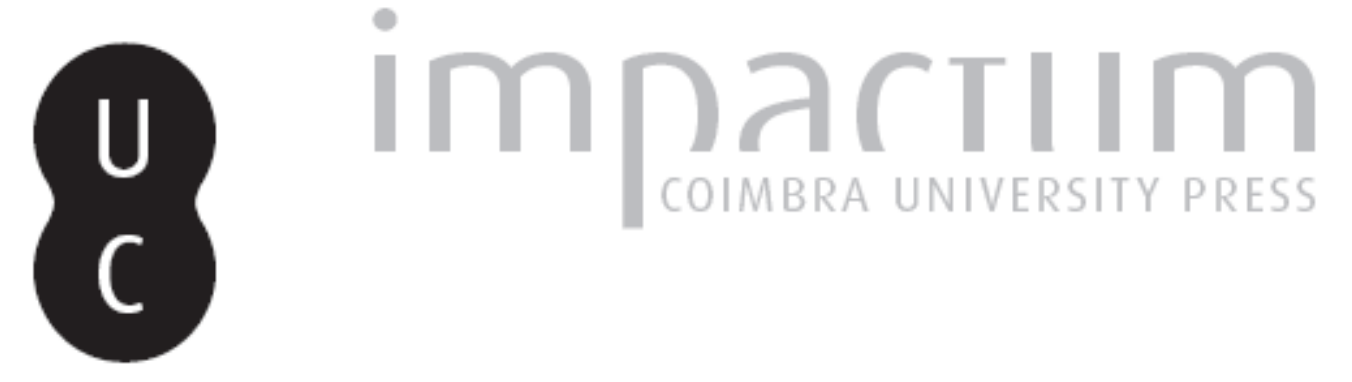

\title{
[Recensão a] Dir. M. Tuñón de Lara, Historia de España, I, Introducción, Primeras Culturas e Hispania Romana
}
Autor(es):
Vilaça, Raquel; D'Encarnação, José
Publicado por: Imprensa da Universidade de Coimbra
URL persistente:
URI:http://hdl.handle.net/10316.2/45622
DOI:
DOI:https://dx.doi.org/10.14195/1647-8657_25_16
Accessed :
26-Apr-2023 13:46:49

A navegação consulta e descarregamento dos títulos inseridos nas Bibliotecas Digitais UC Digitalis, UC Pombalina e UC Impactum, pressupõem a aceitação plena e sem reservas dos Termos e Condições de Uso destas Bibliotecas Digitais, disponíveis em https://digitalis.uc.pt/pt-pt/termos.

Conforme exposto nos referidos Termos e Condições de Uso, o descarregamento de títulos de acesso restrito requer uma licença válida de autorização devendo o utilizador aceder ao(s) documento(s) a partir de um endereço de IP da instituição detentora da supramencionada licença.

Ao utilizador é apenas permitido o descarregamento para uso pessoal, pelo que o emprego do(s) título(s) descarregado(s) para outro fim, designadamente comercial, carece de autorização do respetivo autor ou editor da obra.

Na medida em que todas as obras da UC Digitalis se encontram protegidas pelo Código do Direito de Autor e Direitos Conexos e demais legislação aplicável, toda a cópia, parcial ou total, deste documento, nos casos em que é legalmente admitida, deverá conter ou fazer-se acompanhar por este aviso.

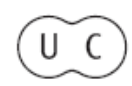


FACULDADE DE LETRAS

INSTITUTO DE ARQUEOLOGIA

CONIMBRIGA

$V O L U M E X X V$

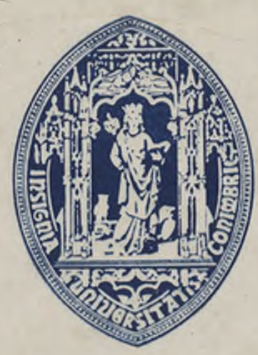

UNIVERSIDADE DE COIMBRA

1986 
várias vezes ao longo do poema, informações de fontes diversas: a base foi a tradução, para latim, de um poema grego de um autor do século i a.C., talvez Cimno; por sua vez, este geógrafo ter-se-ia baseado num périplo massaliota do último quartel do século $\mathrm{li}_{\text {a.C. }}$ e, entretanto, acrescentaria informações recolhidas em Hecateu de Mileto, Helânico de Lesbos, Fileu de Atenas, Parsímico, Heródoto, Tucídides, etc. Esta riqueza informativa das fontes não deixa de ser, porém, frequentemente contraditória, tornando a sua identificação com actuais acidentes de costa, rios ou outros elementos geográficos difícil e, em alguns casos, mesmo impossível, Naturalmente que os geógrafos, particularmente os de geografia antiga, tão pouco estudada entre nós, têm ainda uma importante palavra a dizer.

É óbvio que aos arqueólogos cabe também uma palavra. A constante informação arqueológica, se bem que parcial e insuficiente, é aquela que, à partida, oferece um permanente fio informativo inesgotável. De facto, os comentários ao texto agora traduzido baseiam-se, na sua maioria, não obstante o comentador ser filólogo e não arqueólogo, nos últimos dados que a arqueologia tem proporcionado. É por isso que encontramos reunidos nesta publicação, ao longo das trinta páginas de anotações e, depois, na bibliografia selecta, os estudos mais recentes e importantes sobre vários aspectos da nossa arqueologia proto-histórica.

A opção, para o título do poema, de Orla em vez de Ora, de forma a manter-se o título próximo do original, merece igualmente ser anotada.

Como se sabe, Schulten dedicou a sua vida a esta causa, em particular, ao problema de Tartessos. Iloje, muitos dos seus estudos foram ultrapassados, bem como algumas das interpretações que fez e que materializou no mapa que publicou (Fontes Hispaniae Antiquae I-Avieno: Ora Maritima, 19552). Apesar disso e porque, entretanto, mais nenhum veio a lume, Ribeiro Ferreira optou por o incluir no final do seu estudo, baseando, igualmente, a sua tradução no texto de Schulten.

Enfim, uma obra em que à beleza e rigor do texto em língua portuguesa se alia o extremo cuidado posto por José Ribeiro Ferreira em apontar as pistas de investigação já percorridas e a problemática ainda em aberto — uma feliz concordância entre a literatura e a história.

RAQUEL VILAÇA

Dir. M. Tuñón de Lara, Historia de España, I, Introducción, Primeras Culturas e Hispania Romana, Editorial Labor, 1980, 480 p., ilustrado (XXVI mapas).

Apresenta-se o primeiro tomo de uma nova Historia de Espanha (contam-se mais nove volumes), dirigida por M. Tunón de Lara, lançada, há algum tempo, pela editorial Labor.

Conimbriga, 25 (1986), 227-251 
Deste primeiro volume, que trata das origens do homem até à época romana, ocuparam-se, respectivamente, Miguel Tarradell e Júlio Mangas. Mas, antes, a obra é-nos apresentada pelo seu director que, na introdução, adverte o leitor para o tipo de história que vai encontrar: uma história global.

Na primeira parte, quando se trata a Pré-História, Tarradell interroga-se, com toda a razão, sobre a legitimidade de escrever uma «Prehistoria de España»; se assim for, parte-se de um estado moderno sem nenhuma realidade para o período que se quer estudar, ficando-se, desde logo, com uma visão deformada e mutilada da realidade em estudo. Ao tempo pré-histórico correspondem unidades geográficas, não políticas. A consciência deste problema faz com que o autor ultrapasse muitas vezes as fronteiras espanholas e procure, no espaço hoje português, a outra realidade complementar. Esta opção significa, contudo, que o critério escolhido não é sempre o mesmo e assim, por exemplo, o silêncio é completo no que respeita ao Paleolítico do território português, enquanto que aos concheiros de Muge é dado um lugar de relevo no capítulo do Mesolítico.

Estranhamos que a bibliografia dos anos 70 só casualmente seja referida, por considerarmos que é imprescindível e marca o início de uma nova fase na investigação prehistórica e protohistórica peninsular. Talvez por isso, a origem do megalitismo é ainda atribuída à segunda metade do $3 .^{\circ}$ milénio a.C. (p. 76). Outro lado que parece desactualizado, neste caso só porque recentemente se rasgaram novas pistas (assinalem-se as importantes investigações que Susana Oliveira Jorge tem vindo a desenvolver na região de Chaves), diz respeito à cerâmica da Penha (Guimarães). Tarradell considera-a a antecessora directa da cerâmica castreja, colocando-a, como até há bem pouco tempo se fazia, no Bronze Final.

De leitura fácil e leve, de modo nenhum especializada, é uma obra que sintetiza mais do que analisa, destinada ao grande público ou a iniciados.

Esta primeira parte termina com o estudo da Pré e Protohistória das Canárias e Baleares, importante por ser pouco divulgado.

A segunda parte - Hispania Romana (p. 199-432) - divide-se em: a conquista (p. 209-238), República (p. 239-286) e o Império (de Augusto a Diocleciano) - p. 287-432.

Publicado com data de 1980, e embora inclua na bibliografia obras de 1979, pensamos que a redacção do trabalho é bastante anterior a essa data, uma vez que não se têm em conta dados que a investigação peninsular já adquirira, por exemplo no domínio das divindades indígenas. Este caso não é ímpar na historiografia, pelo que somos de parecer que, de futuro, deverá haver, por parte dos investigadores, a preocupação de indicarem o termo cronológico da elaboração da obra, inclusive para sua salvaguarda, não vão os críticos acoimá-los de pechas de que não são culpados.

Júlio Mangas começa por discutir problemas metodológicos: as fontes; as várias maneiras de encarar a história hispânica; a necessidade de distinguir latinização de romanização (p. 207). Afirma ser seu objectivo estudar o desaparecimento ou a transformação das estruturas indígenas da Hispânia 
perante as estruturas romanas (p. 208). Dizendo-se defensor do materialismo histórico como concepção globalizante (p. 207), J. Mangas considera que o domínio político não produz mecanicamente mudanças radicais, de modo que se torna necessário ver em que circunstâncias e em que áreas geográficas e níveis estruturais houve, de facto, mudança, pois foi o desigual desenvolvimento dos povos pré-romanos que condicionou a sua integração.

No respeitante à República, interessou-nos a discussão da existência, ou não, de latifúndios na Hispânia: J. Mangas é de opinião que houve concentração da propriedade mas não concentração de terras com vista à formação de latifúndios; aliás, acentua, a política administrativa romana não preconizava a criação de grandes latifúndios do Estado na Hispânia (p. 258). No entanto, não foi a agricultura mas sim a actividade mineira a primeira economia peninsular de ponta ao tempo dos Romanos (p. 266).

O início da III parte (p. 287) e, depois, do capítulo sobre a organização económica e social da Hispânia imperial (p. 315), são pretexto, mais uma vez, para a abordagem de questões metodológicas. Uma história desse período, afirma o Autor, tanto deve evitar cingir-se à apresentação de acontecimentos anedóticos peninsulares desgarrados do contexto geral do Império como resumir-se à aplicação automática à Hispânia dos dados conhecidos da história imperial de Roma e da Península Itálica. A elaboração de sínteses é, pois, difícil e - quantas vezes - prematura. E, a esse propósito, o panorama bibliográfico de que dispomos abrange, bastas vezes com o rótulo de síntese, dados acumulados sem crítica, estudos de questões muito concretas nem sempre primordiais, trabalhos meramente arqueológicos. Assim por exemplo - nota Júlio Mangas - não se pode falar, sem mais, de uma organização social, em que ora avulta a persistência da tradição indígena, ora sobressai a sociedade de tipo romano (p. 357).

Largas passadas deu a investigação arqueológico-histórica peninsular no último decénio. Os múltiplos e importantes achados epigráficos, o maior intercâmbio científico dos historiadores e arqueólogos de Espanha e de Portugal, a publicação mais rigorosa e sistemática dos relatórios das escavações - são, entre outros, os factores dominantes dessa renovação. Mas esta síntese elaborada por J. Mangas é, sem dúvida, um marco válido, ponto de partida para novas análises de que outras sínteses hão-de aproveitar.

Assim, a nossa recente investigação sobre o conventus pacensis permite-nos duvidar da existência: de um colégio funerário em Balsa (p. 366, mapa $2-$ com que fundamento?), de um colégio de jovens em Pax Iulia (p. 368) só porque aí se regista uma inscrição (duvidosa) à deusa Juventus, ou de um colégio juvenil em Ebora com funções semi-militares (p. 369). Também não dispomos de documentação que justifique a existência de um templo a Cibele na Egitânia (p. 429). Mangas considera os amici dedicantes das inscrições como um conselho técnico que acessoraria os magistrados (p. 371): não menosprezando esse eventual papel de assessoria, pensamos que os amici são, sobretudo, a clientela político-social de alguém. Entre os médicos (p. 380), haveria que citar também C. Attius Ianuarius, medicus pacensis, documentado em Miróbriga (CIL II 21). 
Na página 234, Scallabis é classificada município cesariano: seria, de preferência, uma colónia, como Pax Iulia (que não é citada). O mapa das fábricas de salga em Hispânia e na Mauritânia Tingitana (p. 252) retirado da obra de M. Ponsich e M. Tarradell (1965), teria necessitado de actualização, até porque traz, no que se refere ao litoral português, muitos erros nas designações toponímicas e na sua localização. Cita-se F. Bajo como autor do mapa da pág. 270 - mas não vimos qualquer obra sua referida na bibliografia que, por ordem alfabética de autores, complementa o volume. Aliás, apresenta-se também: uma tábua de abreviaturas e siglas; uma cronologia comparada dos feitos políticos e militares, e dos dados económicos e sociais com os factos da história geral romana.

Facilitam a consulta os índices: onomástico, toponímico, de mapas, geral.

RAQUEL VILAÇA

JosÉ D'ENCARNAÇÃO

Enrique Cerrillo Martin de Cáce res, La vida rural romana en Extremadura.

Servido de Publicaciones de la Universidad de Extremadura. Cáceres, 1984. 148 p., ilustrado. [I.S.B.N.: 84-600-3711-8].

Não se trata de um livro sobre a vida quotidiana dos agricultores romanos nem de um manual de arqueologia rural. É, sobretudo, uma história da agricultura na Estremadura espanhola; um primeiro ensaio de síntese do que se sabe, os problemas que se levantam à investigação, as hipóteses de os resolver. Uma reflexão levada a cabo pelo autor como membro da equipa que, no Departamento de Pré-História e Arqueologia da Universidade de Extremadura, tem como um dos seus objectivos científicos procurar explicar, sem tabus, sem preconceitos e sem complexos de inferioridade, «a vida campesina e os comportamentos agrários fortemente arraigados na região e ainda hoje nela vigentes» (p. 13).

Em linguagem acessível, E. Cerrillo mostra, no I capítulo (p. 19-45), como, desde os tempos pré-históricos, se originou a exploração agrária na Estremadura. O II capítulo aborda as fases da romanização e as transformações paulatinas que ela foi introduzindo: os primeiros estabelecimentos rurais romanos (p. 52-65), a partir dos limites mais afastados dos termos urbanos, e a segunda fase da ocupação rural que já supõe «um autêntico ordenamento territorial» (p. 75).

No cap. Ill, Os Sítios (p. 81-126), E. Cerrillo não apresenta, como o título poderia fazer supor, um catálogo das villae estremenhas ou a sua caracterização arquitectónica individualizada. Aproximando-se muito embora de um esquema descritivo de tipo arqueológico, começa por referir os factores que levavam à escolha da localização das villae (por exemplo, as caracte- 